\title{
Os vínculos viventes entre o pensamento de Oliveira Vianna e o de Émile Durkheim
}

\author{
The links between Oliveira Vianna's thought and the theory of Émile Durkheim
}

\author{
Felipe Fontana \\ Doutorando em Ciência Política \\ Universidade Federal de São Carlos - UFSCar \\ e-mail: buthjaum@yahoo.com.br
}

RESUMO Este artigo tem a finalidade de apresentar os principais resultados da dissertação "A Presença de Émile Durkheim em Oliveira Vianna: Contribuições ao Pensamento Social e Político Brasileiro". Nessa pesquisa, realizamos algumas análises que tinham o objetivo de estabelecer ligações entre o pensamento de Émile Durkheim e o de Oliveira Vianna. Para isso, elencamos, através de uma investigação bibliográfica prévia e de uma pesquisa no Museu Casa de Oliveira Vianna, uma série de eixos conceitos e temáticos que melhor evidenciavam os vínculos existentes entre ambos os autores; são eles: as categorias de Consciência Coletiva, Solidariedade Social, Morfologia Social e as noções de Estado e de Corporativismo. Neste estudo, elegemos a Sociologia do Conhecimento como a fonte dos pressupostos metodológicos de nossas tarefas. Assim, realizamos comparações bibliográficas entre o pensamento de ambos os pensadores; analisamos os contextos históricos dos autores estudados e a percepção que eles tinham de suas realidades; e desenvolvemos um trabalho no acervo de Oliveira Vianna com a finalidade de averiguar se as obras ali presentes tinham ligação com pensamento durkheimiano. De maneira geral, acreditamos que nossa pesquisa evidencia que há um importante vínculo entre o pensamento de ambos os intelectuais; além disso, ela também mostra como algumas idéias e conceitualizações durkheimianas foram transpostas, de um modo específico, para o cenário e a vida intelectual brasileira.

PalaVRas-Chave Oliveira Vianna; Émile Durkheim; Pensamento Social e Político Brasileiro; Solidariedade Social; Morfologia Social; Estado; Corporativismo.

ABSTRACT This article aims to present the main results of the dissertation The Presence of Émile Durkheim in Oliveira Vianna: Contributions to the Brazilian Social and Political Thought. In this research, we conducted some analyzes that were designed to establish links between the Theory of Emile Durkheim and Oliveira Vianna' Thought. For this, we selected through a preliminary literature study and a search at the Museum Casa de Oliveira Vianna, a number of concepts and thematic axes that best evidenced links between both authors, they are: the categories of Collective Consciousness, Social Solidarity, Social Morphology and the notions of State and Corporatism. In this study, we chose the Sociology of Knowledge as the source of the methodological 
assumptions of our activities. Thus, we conducted bibliographic comparisons between the thought of both thinkers, we analyze the historical context of the studied authors focusing on the perception they had of their realities and we developed a work in Oliveira Vianna's collection in order to ascertain whether the works present there had connection with Durkheimian Thought. In general, we believe that our research shows that there is an important link between the thinking of both intellectuals and, moreover, it also shows how some Durkheimian Ideas and Conceptualizations were transposed in a specific way to the Brazilian intellectual life.

KEYWORDS Oliveira Vianna; Émile Durkheim; Brazilian Social and Political Thought; Social Solidarity; Social Morphology; State; Corporatism.

\section{Introdução}

Este artigo tem a finalidade de apresentar os resultados da pesquisa denominada A Presença de Émile Durkheim em Oliveira Vianna: Contribuições ao Pensamento Social e Político Brasileiro. Para isso, apresentaremos as principais idéias e conclusões desse trabalho levando em consideração a maneira como a dissertação resultante dele está disposta em sua versão original. Ou seja, nessa Introdução, versaremos acerca do objeto e dos objetivos de nossa pesquisa assim como da metodologia empregada para realizá-la. Em seguida, exporemos como as hipóteses que guiaram nosso trabalho foram constituídas; tal exposição, por sua vez, será divida em quatro tópicos (respeitando a sequência dos capítulos da dissertação). Por fim, concluiremos este artigo evidenciando os principais resultados de nosso trabalho.

De maneira geral, nossa pesquisa tinha como objeto a compreensão dos vínculos existentes entre o pensamento de Oliveira Vianna e o de Émile Durkheim. Para realizar essa tarefa nós estabelecemos alguns objetivos, os quais tinham a finalidade de melhor orientar nossas análises justamente porque eles mediavam a ligação entre ambos os autores através de alguns eixos conceituais e temáticos; ou seja, segmentavam nossa investigação em abordagens específicas, facilitando assim, o entendimento desse objeto de grande envergadura. Para melhor compreender essa afirmação é necessário expor a maneira pela qual esse objeto e esses objetivos de pesquisa foram constituídos.

Ao passo que entramos em contato com uma dada bibliografia que busca comentar Oliveira Vianna notamos a menção constante de uma possível relação entre o pensamento do intelectual brasileiro e as idéias do sociólogo francês. O que nos instigou foi justamente a pouca solidez e falta de embasamento destas afirmações; ou seja, ao passo que os comentadores do pensador niteroiense mencionavam determinados vínculos entre Oliveira Vianna e Émile Durkheim eles não os justificavam ou apresentavam ao leitor evidências mais precisas disso. Evaldo Vieira, Maria Stella Martins Bresciani, José Murilo de Carvalho, Luis Werneck Viana e Vasconcelos Tôrres são exemplos de alguns pesquisadores que mencionam um vínculo entre os autores estudados sem, contudo, se aprofundar nessa questão.

Todavia, as menções desses estudiosos eram sempre acompanhadas por algumas hipóteses; ou seja, para eles, o vínculo existente entre Émile Durkheim e Oliveira Vianna poderia ser compreendido se fosse levado em consideração alguns conceitos ou noções. Por exemplo, na obra Oliveira Vianna - sua Vida e sua Posição nos Estudos Brasileiros de Sociologia, Vasconcelos Tôrres, ao enaltecer a importância dos estudos sociológicos de Oliveira Vianna, afirma que não houve no Brasil um pensador anterior ao sociólogo fluminense que tratou, assim como Émile Durkheim, os fatos sociais como coisas, ou seja, objetivamente. Para o biógrafo:

Sociologia como o estudo das ações e relações homens entre si e de suas condições e consequências, na lição de Morris Ginsberg; sociologia como ciências especial que trata das fórmulas últimas e irredutíveis em que aparece o laço psíquico que une os homens em sociedade, na tese de Vierkandt; sociologia tratando os fatos sociais como coisas, segundo ensina Émile Durkheim em 'As Regras do Método Sociológico'; sociologia aplicada e objetivamente considerada do ponto de vista técnico, essa sociologia praticada não foi pelos antecessores de Vianna. (Tôrres, 1956, p. 69). 
Para Vasconcelos Tôrres, há contribuições durkheimianas ao pensamento de Oliveira Vianna e as mesmas podem ser visualizadas de modo mais claro quando pensamos na questão do método. Assim como o biógrafo, uma gama significativa de comentadores de Oliveira Vianna lançam algumas pistas, indícios e vestígios acerca de uma possível ligação entre o pensador brasileiro e o sociólogo francês. Evaldo Vieira (1981), por exemplo, afirma que é possível enxergar ligações entre o pensamento de Émile Durkheim e o de Oliveira Vianna que são mediadas pela noção de corporativismo. Maria Stella Martins Bresciani (2007) afirma que as contribuições durkheimianas $^{1}$ ao pensamento de Oliveira Vianna estão circunscritas ao conceito de Solidariedade Social. Já Luiz Werneck Vianna (1991) identifica semelhanças em relação à perspectiva de Estado inerente ao pensamento de ambos os autores.

Assim, ao passo que analisamos uma dada bibliografia que busca comentar Oliveira Vianna conseguimos apreender de maneira direta um objeto de pesquisa, qual seja: a necessidade de compreender a ligação entre o pensamento de Oliveira Vianna e o de Émile Durkheim. A lacuna que possibilita a investigação desse objeto se dá porque muitos comentadores mencionam um vínculo entre ambos os autores sem se aprofundar no entendimento do mesmo. Contudo, ao realizar essas menções, estes comentores fornecem algumas pistas para compreender as contribuições durkheimianas ao pensamento do intelectual brasileiro.

Resumindo uma importante parte de nosso trabalho que visava mensurar e apresentar os indícios e pistas deixadas pelos comentadores de Oliveira Vianna, os quais foram denominados por nós como eixos conceituais e temáticos, podemos afirmar que a ligação existente entre ambos os autores pode ser compreendida quando levamos em consideração a presença dos seguintes conceitos e noções no pensamento de Oliveira Vianna: o conceito de Solidariedade Social; as noções de Estado e de Corporativismo; e a Perspectiva Metodológica.

Segundo os comentadores, seriam esses eixos conceituais que possibilitariam enxergar uma ligação entre ambos os pensadores. Contudo, nesta pesquisa, a pertinência de compreender a relação entre $o$

\footnotetext{
Vale lembrar que para a autora essas contribuições durkheimianas fazem parte de uma corrente de pensamento francesa que tratava da idéia de Solidariedade Social (Solidarismo Francês). Tal corrente, segundo ela, teria influenciado Oliveira Vianna. No entanto, a autora destaca a importância do sociólogo francês no que tange a relevância destas idéias para além da França; ou seja, graças a Émile Durkheim e suas teorizações sobre o tema que estas idéias tiveram grande sucesso e respaldo em outros países.
}

pensamento deles mediada por esses conceitos foi testado por nós de duas maneiras. A primeira foi realizando aproximações entre o pensamento de ambos os autores através de suas próprias obras². E a segunda foi por meio da pesquisa realizada no Museu Casa de Oliveira Vianna.

Ao passo que visitávamos as obras durkheimianas e os manuais de Sociologia que tinham relação com o pensamento durkheimiano presentes no acervo do intelectual fluminense, nós passamos a considerar a viabilidade de compreender a ligação existente entre o pensamento de ambos os autores por determinados eixos conceituais e temáticos diferenciados daqueles sugeridos pelos comentadores. Por exemplo, a questão vinculada à perspectiva metodológica, apontada por Vasconcelos Tôrres, quando contrapostas com o material por nós analisado no museu se mostrou pouco produtiva para entender o vínculo existente entre os dois autores; afinal, não encontramos nem marcações, nem anotações de Oliveira Vianna que ajudassem a desvendar essa questão. Contudo, a pesquisa do museu também foi importante para edificar outros eixos conceituais e temáticos. O conceito de Consciência Coletiva e a noção de Morfologia Social, que não foram mencionados pelos comentadores por nós estudados e que aparecem com frequência em obras de Oliveira Vianna, foram constantemente marcados e sublinhados pelo intelectual brasileiro nas obras durkheimianas e nos manuais que tinham ligação com o pensamento do intelectual francês, despertando assim, nosso interesse em relação a estas categorias.

Dessa forma, após a realização destas duas atividades (comparações bibliográficas diretas e análise do material encontrado no museu), elegemos e edificamos, definitivamente, os eixos conceituais e temáticos que guiaram a compreensão do nosso objeto de pesquisa. Assim, notamos que era de grande importância para entender a ligação de ambos os autores realizar a análise dos usos que Oliveira Vianna fez dos conceitos durkheimianos de Solidariedade Social e Consciência Coletiva; e das idéias de Émile Durkheim voltadas às noções de Estado, de Corporativismo e de Morfologia Social.

Para entender esse objeto de pesquisa e perseguir esses objetivos elegemos a Sociologia do Conhecimento como a fonte dos pressupostos metodológicos de nosso trabalho. Nessa pesquisa, realizamos um amplo exame dessa área do conhecimento com a finalidade

\footnotetext{
${ }^{2}$ Comparamos, por exemplo, se o conceito de Solidariedade Social definido por Émile Durkheim em A Divisão do Trabalho Social tinha significação semelhante com o empregado por Oliveira Vianna em Populações Meridionais do Brasil (1938) e Instituições Políticas Brasileiras (1999).
} 
de mensurar quais são suas efetivas contribuições para nossa pesquisa. De maneira geral, vimos como a Sociologia do Conhecimento liga-se com nosso estudo e nos oferece importantes caminhos e orientações para pensarmos e problematizarmos a constituição do conhecimento. Nesse sentido, notamos que era de fundamental importância compreender os contextos históricos de ambos os autores e a interpretação que eles faziam de suas realidades, para assim, estabelecer paralelos e construir ligações entre os pensadores pesquisados levando em consideração algumas questões "extrateóricas"3.

Considerar a necessidade de identificar e relacionar estas dimensões "extrateóricas" com nosso objeto de pesquisa evidencia nossa preocupação com a questão central posta pela Sociologia do Conhecimento, qual seja: o profundo entendimento dos vínculos existentes entre o nascimento de determinados conhecimentos com os contextos e as condições históricas nas quais seu criador ou criadores estavam localizados, buscando estabelecer assim, as relações de influência entre o "conhecimento e a existência".

$\mathrm{Na}$ atualidade, notamos que há no Pensamento Social e Político Brasileiro uma gama significativa de estudos e pesquisas que buscam compreender determinados autores levando em consideração as importantes mediações entre seus pensamentos e os contextos nos quais eles foram constituídos. Lilia Mortriz Schwarcz e André Botelho, em recente artigo denominado Pensamento Social Brasileiro, um Campo Vasto Ganhando Forma, assinalam o quão expressiva é a presença de trabalhos que encaram com seriedade os vínculos entre pensador, pensamento, contextos históricos e contextos de produção do conhecimento:

Em consonância com a produção e o debate internacionais no domínio das ciências sociais, podem-se assinalar, ainda, algumas alterações importantes nesse campo de pesquisas [Pensamento Social Brasileiro], como o interesse pelos processos sociais não apenas de produção, mas também de aquisição, transmissão e recepção das diferentes formas de conhecimento; a visão dos detentores do conhecimento como um grupo maior e mais variado do que antes; o interesse pela vida intelectual cotidiana de pequenos grupos, círculos ou redes vistas como unidades fundamentais que constroem e difundem o conhecimento. (Botelho e Schwarcz, 2011: p. 12).

\footnotetext{
3 Termo cunhado por Karl Mannheim na obra Ideologia e Utopia (1976: p.288) que é também denominado pelo autor como "fatores existenciais, em contraposição aos fatores puramente teóricos".
}

Acerca da Sociologia do Conhecimento, também verificamos que não há grandes discussões junto aos seus estudiosos que estão voltadas ao entendimento dos meios pelos quais essa tarefa (compreensão da relação vivente entre o conhecimento e a existência) deve ser realizada, ou seja, sem evidenciar claramente as questões metodológicas e técnicas que envolvem uma pesquisa ligada a esta área do saber. Dessa forma, e preocupados com esta outra lacuna, discorremos sobre os meios práticos que auxiliaram em nossa pesquisa; ou seja, ponderamos sobre o trabalho desenvolvido no Museu Casa de Oliveira Vianna, os desafios encontrados na pesquisa, as escolhas das obras analisadas, o tratamento dado a elas, a necessidade de prestar atenção no contexto de produção do autor e nos manuais introdutórios presentes no acervo do pensador fluminense.

Sobre essa discussão, em nossa pesquisa, destaca-se o papel dos manuais ${ }^{4}$ introdutórios como importantes ferramentas utilizadas por Oliveira Vianna com a finalidade de acessar determinados idéias de autores estrangeiros. Quanto a isso, notamos o quão frequente é marcado e sublinhado pelo intelectual brasileiro determinados conceitos e idéias durkheimianas traduzidas e interpretadas por outros autores. Além disso, esses manuais são na maioria franceses e neles é possível identificar uma importante presença durkheimiana.

Por fim, no próximo tópico apresentaremos de maneira sucinta a importante contribuição da Sociologia do Conhecimento para a nossa pesquisa, qual seja, a necessidade de compreender os vínculo dos autores e suas realidades e a contribuição dessa questão para o nosso trabalho.

\footnotetext{
${ }^{4}$ Segundo Simone Meucci, os manuais introdutórios foram frequentemente utilizados pelos intelectuais brasileiros no início do século XX que, devido à dificuldade de se obter as obras diretas/ originais de autores estrangeiros, recorriam a esta alternativa; de acordo com a estudiosa, dentre os autores estrangeiros da escola francesa que mais foram traduzidos e reproduzidos em nossos manuais destaca-se Émile Durkheim: "O mais representativo e o mais influente sociólogo membro dessa 'escola' é certamente Émile Durkheim, cujas contribuições ocupam as páginas de muitos de nossos manuais. Especialmente os livros 'Sociologia Criminal' (1915) de Paulo Egydio Carvalho, 'Princípios de Sociologia' (1935) de Fernando de Azevedo, 'O que é sociologia' (1935) de Rodrigues Merèje, e 'Sociologia Educacional' (1940) de Fernando de Azevedo são importantes veículos divulgadores das idéias de Durkheim. Seus autores pretendiam, por meio da difusão dos conceitos e das investigações do sociólogo francês, legitimar a sociologia em nosso meio intelectual". (Meucci, 2001: p. 127).
} 


\section{A Importância dos Contextos Históricos de Émile Durkheim e de Oliveira Vianna para a Compreesão da Ligação Existente entre Eles}

Nesta parte da pesquisa, buscamos apresentar e compreender certos vínculos entre Émile Durkheim e Oliveira Vianna que fogem de uma perspectiva teórica comparada. Ou seja, buscamos entender o vínculo de ambos os autores analisando determinadas pistas extrateóricas. Nesse sentido, foi levando em consideração o contexto histórico dos pensadores pesquisados e a interpretação que os mesmo faziam desse momento que delineamos algumas importantes aproximações entre eles e suas teorias.

Dessa forma, notamos que, ao se depararem com a história de suas sociedades e nações, ambos os intelectuais notam processos de desintegração e rupturas, e é justamente isso que possibilita que o pensador brasileiro faça uso de determinados conceitos ou noções durkheimianas. As categorias durkheimianas emprestadas por Oliveira Vianna emergiram de uma interpretação impar que o sociólogo francês fazia da França. Essa interpretação gerou uma série de diagnósticos que possui certa similitude com algumas posições de Oliveira Vianna sobre o Brasil. Acreditamos que é por conta dessas semelhanças interpretativas que o pensador brasileiro pôde fazer uso de conceitos e noções cunhadas por Émile Durkheim para entender o Brasil e sua formação.

Por exemplo, no caso de Émile Durkheim o conceito de Solidariedade serviu para medir o quão agregada ou desagregada se encontrava a França frente ao seu processo de modernização e reconstrução durante a Terceira República Francesa. Já para Oliveira Vianna este mesmo conceito serviu para constatar a ausência de laços de integração entre os homens de nosso Brasil Colônia. Dessa forma, podemos afirmar que a não integração diagnostificada e percebida por ambos os autores em sua suas respectivas sociedades pode ser encarada como o fio condutor da utilização do conceito de Solidariedade Social feita por eles.

Também queremos deixar claro que tencionamos ao máximo algumas de nossas hipóteses e idéias para compreender a ligação entre Émile Durkheim e Oliveira Vianna. Dessa forma, por mais que existam essas determinações extrateóricas que possibilitem a utilização de conceitos durkheimianos por Oliveira Vianna não acreditamos que o intelectual brasileiro apenas copiou e reproduziu de maneira vã aquilo que informava o sociólogo francês em algumas de suas teorizações; ou seja, Oliveira Vianna, ao passo que emprestou algumas noções de Émile Durkheim não revelou uma extrema contradição entre aquilo que pensava sobre Brasil e aquilo que o conceito durkheimiano significava justamente porque o pensador niteroiense conservava uma interpretação específica acerca da realidade e da formação brasileira, a qual, segundo nossa visão, se alinhava, em determinados pontos, com a maneira como Émile Durkheim enxergava, analisava e, principalmente, interpretava o contexto francês vivido por ele.

Assim, fica claro que acreditamos que Oliveira Vianna não reproduziu determinadas idéias durkheimianas adequando-as a realidade brasileira de modo inapropriado; ou seja, que ele moldou sua visão sobre o Brasil porque utilizou como lente interpretativa alguns conceitos durkheimianos ${ }^{5}$. É justamente o contrário, afinal, todo o esforço despendido por nós nessa parte da pesquisa mostrou que o autor só fez uso desses conceitos porque eles, de alguma forma, estavam sintonizados com sua interpretação, teorização e idéias acerca do Brasil e sua formação. Nesse sentido, acreditamos que o intelectual francês integrou contribuições durkheimianas ao seu entendimento e a sua leitura acerca do Brasil.

Antes de terminarmos esse tópico devemos evidenciar a maneira que procedemos para chegar a estas conclusões. As visões durkheimianas acerca da realidade francesa expostas em alguns de seus $\operatorname{textos}^{6}$ e as idéias de Oliveira Vianna acerca da

\footnotetext{
5 Identificar essa questão é de extrema importância no que tange a discussões basilares presentes em nosso Pensamento Social e Político. Afinal, muitos autores dessa corrente são acusados, por vezes, de estabelecerem uma interpretação genuína e específica sobre o Brasil quando, na verdade, estão apenas reproduzindo conceitos, idéias e esquemas estrangeiros, enxergando, dessa forma, na realidade brasileira, problemas ou quadros interpretativos estranhos ao que ela realmente é; fragilizando assim, a propriedade das hipóteses e das argumentações destes grandes pensadores.
}

${ }^{6}$ Destaca-se aqui a obra Educação e Sociologia. Neste trabalho, o intelectual francês expõe, mesmo que indiretamente, muitas das suas percepções sobre a França e defende, dentre outras coisas, a Educação como um método importante para a constituição de uma França, de fato, unificada. Todavia, também verificamos em outras obras durkheimianas e nas palavras de alguns comentadores a especificidade da visão do intelectual francês acerca da realidade francesa por ele vivida; tal visão, na maioria das vezes, volta-se constantemente para a necessidade da criação de fortes laços de solidariedade e moralidade. Por exemplo, na obra Educação e Sociologia, a Educação, os Educadores e a Escola, para o intelectual francês, possuem uma função importante em meio à sociedade francesa. Se por um lado eles devem refletir os paradigmas mais importantes que regem essa civilização, respeitando-os, por outro, eles devem, com a ajuda do Estado, transmitir aos indivíduos e, principalmente, neles edificar, os princípios que regem o meio social. Nesse caso, essa proposta se alinha com a perspectiva da Terceira República Francesa que afirma que era necessário unificar a França, fazê-la uma só. Segundo o sociólogo francês "Há, nessas divergências, um fato impossível de dissimular, e cuja consideração se impõe ao espírito dos educadores. É o de que não se deve reconhecer à maioria o direito de impor suas idéias aos filhos dos indivíduos 
realidade brasileira, também expostas em muitos de seus trabalhos, foram as fontes para traçarmos esses importantes paralelos interpretativos. Na pesquisa, obviamente, a apresentação dessas interpretações aparecem de modo anterior às afirmações postas tão enfaticamente nesse tópico, integrando assim, toda nossa argumentação. Não realizamos aqui a exposição desse material por conta da necessidade de síntese exigida pelo artigo.

\section{Vínculo entre Oliveira Vianna e Émile Durkheim Mediado pelo Conceito de Solidariedade Social e Consciência Coletiva}

Os próximos três tópicos apresentarão os resultados de nossas investigações acerca dos objetivos da pesquisa. Ou seja, primeiramente falaremos de como os conceitos de Consciência Coletiva e de Solidariedade Social são de grande importância para compreender o vínculo entre Oliveira Vianna e Émile Durkheim. Em seguida, mostraremos como a noção de Estado e de Corporativismo nos ajuda a aproximar ambos os pensadores. E, por fim, como o conceito de Morfologia Social possibilita o entendimento de outras ligações entre os pensamentos dos intelectuais estudados.

Vale lembrar que todos os tópicos que tratam da investigação dos eixos conceituais e temáticos analisados por nós respeitarão a maneira como construímos a argumentação de nossa pesquisa; ou seja, apresentaremos a definição durkheimiana dos conceitos e noções estudadas; evidenciaremos como estes eixos conceituais e temáticos são definidos e empregados por Oliveira Vianna; e exporemos como tais categorias aparecem nas marcações feitas pelo sociólogo brasileiro em obras durkheimianas ou nos manuais vinculados ao pensamento durkheimiano por nós analisados no Мuseu Casa de Oliveira Vianna. Contudo, deve-se ficar claro, que abriremos mão de

\footnotetext{
em minoria. A escola não deve ser propriedade de um partido; e o mestre faltará aos seus deveres quando empregue a autoridade de que dispõe para atrair seus alunos à rotina de seus preconceitos pessoais, por mais justificados que eles pareçam. Mas, a despeito de todas as dissidências, há na base de nossa civilização certo número de princípios que, implícita ou explicitamente, são comuns a todos, ou pelo menos que bem poucos ousam a negar em sã consciência: o respeito da razão da ciência, das idéias e sentimentos em que se baseia a moral democrática. É função do Estado é proteger esses princípios essenciais, fazê-los ensinar em suas escolas, velar para que eles não fiquem ignorados pelas crianças de parte alguma, zelar pelo respeito que lhes devemos. Há, a este propósito, uma ação certa a exercer, que talvez seja tanto mais eficaz, quanto menos agressiva e menos violenta pareça, contida, como deve ser, nos limites da sábia tolerância. [1922] (Durkheim, 1972: p. 49).'
}

um ou dois exemplos comparativos e que esta é uma diferença contundente em relação a nossa pesquisa, a qual, por sua vez, possui uma extensa exposição dos resultados de nosso trabalho no acervo do intelectual fluminense.

O conceito de Consciência Coletiva apresentado por Émile Durkheim na obra A Divisão do Trabalho Social expressa de maneira precisa a superioridade da sociedade em detrimento do indivíduo 7 . Para o sociólogo francês, este conceito traduz o conjunto de sentimentos e crenças que são partilhados por uma maioria em uma dada sociedade. Segundo ele, esse conjunto de crenças e sentimentos revela aquilo que um dado agrupamento social acredita e partilha. Além disso, o conjunto de crenças de uma dada coletividade tem a importante característica de perdurar, constituindo assim, uma continuidade na história daquilo que caracteriza um determinado agrupamento social (suas crenças, costumes, valores, leis, normas, tradições etc.). Nesse sentido, para pensador francês, notamos:

O conjunto das crenças e dos sentimentos comuns à média dos membros de uma mesma sociedade forma um sistema determinado que tem vida própria; podemos chamá-lo de consciência coletiva ou comum. Sem dúvida, ela não tem por substrato um órgão único; ela é, por definição, difusa em toda a extensão da sociedade, mas tem, ainda assim, características específicas que fazem dela uma realidade distinta. De fato, ela

\footnotetext{
Deve-se ficar claro que essa característica do conceito de Consciência Coletiva fica evidente quando circunscrita à obra $A$ Divisão do Trabalho Social. Por mais que seja evidente, em alguns trabalhos de Émile Durkheim, a superioridade do social em relação ao indivíduo isso não significa afirmar que o grau de autonomia dos homens, dentro da teoria durkheimiana, é nulo. Leituras mais delicadas do pensamento durkheimiano possibilita enxergar novas interpretações acerca dessa questão. Um dado importante é a mudança significativa realizada pelo autor na obra As Formas Elementares da Vida Religiosa. Nesse trabalho o sociólogo francês não faz uso do conceito de Consciencia Coletiva com tanta força como em A Divisão do Trabalho Social. Adicionado a isso, o uso do conceito de Representação Social traduz uma contundente mudança/substituição. Como Oliveira Vianna não entrou em contato com As Formas Elementares da Vida Religiosa, assim como com outros trabalhos durkheimianos que não fossem A Divisão do Trabalho Social e As Regras do Método Sociológico, acreditamos que não era possível por parte do pensador brasileiro vislumbrar interpretações alternativas acerca desta importante questão (a relação entre indivíduo e sociedade) presente no pensamento durkheimiano ou, mais precisamente, identificar as nuances, mudanças e especificidades da teoria cunhada pelo intelectual francês. Além disso, os manuais analisados por nós não tinham a função de trabalhar a história de determinados conceitos presentes no pensamento de Émile Durkheim; estas obras quando mencionavam ou tocavam em conceitos durkheimianos, em especial o de Consciência Coletiva e de Solidariedade Social, não tinham a finalidade de tratar da história do mesmo ou de apresentar a sua significação nas diferentes obras de Émile Durkheim. As definições dos conceitos durkheimianos presentes nesses manuais são bem recortados e, em certo sentido, limitados justamente por isso.
} 
é independente das condições particulares em que os indivíduos se encontram: eles passam, ela permanece. [1893] (Durkheim, 1995: p. 50).

Em Populações Meridionais do Brasil, a utilização do conceito de Conceito de Consciência Coletiva é realizada apenas uma vez pelo intelectual niteroiense. Por vezes, categorias como "Psicologia Social", "Psiquê Coletiva", "Psiquê Social", "Mentalidade Social" ou "Mentalidade Coletiva" aparecem nos escritos do autor com um significado muito próximo daquele que Émile Durkheim dá a esta categoria. Nesse sentido, atentaremos agora para a menção específica que Oliveira Vianna faz desse conceito durkheimiano na obra em questão:

Essa aristocracia constitui, como veremos, o centro de polarização dos elementos arianos da nacionalidade. Nos seus sentimentos e volições, nas suas tendências e aspirações, ela reflete a alma peninsular nas suas qualidades mais instintivas e estruturais. São realmente essas qualidades que formam ainda hoje o melhor do nosso caráter. Com as tintas das suas peculiaridades é que se colorem, na intimidade da nossa consciência coletiva, os nossos mais recônditos ideais. [1920] (Vianna, 2005: p. 87).

Nessa citação, o conceito de Consciência Coletiva possui um significado próximo ao dado por Émile Durkheim, afinal, ele é empregado com a intenção de sintetizar a idéia de um conjunto de regras, tradições, costumes, modos e, sobretudo, valores brasileiros. No entanto, não encontramos marcações sobre esse conceito nos manuais consultados por Oliveira Vianna em datas anteriores à publicação de Populações Meridionais do Brasil ${ }^{8}$. Felizmente, Oliveira Vianna faz um maior uso do conceito de Consciência Coletiva na obra Instituições Políticas Brasileiras [1949] ${ }^{9}$, possibilitando assim, comparações entre as utilizações do conceito feitas pelo sociólogo

\footnotetext{
${ }^{8}$ Para compreender nosso objeto de pesquisa e defender nossas hipóteses realizamos nesse trabalho, basicamente, comparações entre os conceitos durkheimianas incorporados por Oliveira Vianna e aquilo que foi lido e marcado por ele acerca destas categorias em obras durkheimianas ou nos manuais vinculados ao pensamento do intelectual francês. Deve-se ficar claro que realizamos essas atividades respeitando a questão cronológica, ou seja, caso as passagens de Oliveira Vianna presentes em Populações Meridionais do Brasil [1920] fossem utilizadas, nós as comparávamos apenas com as obras datadas e consultadas por Oliveira Vianna nos anos anteriores à publicação deste clássico estudo.

9 Um exemplo de utilização do conceito de Consciência Coletiva feita por Oliveira Vianna em Instituições Políticas Brasileiras [1949] é o seguinte: "Os nossos 'estados de consciência coletiva' mais altos, mais intensos, mais amplos têm sido efêmeros, frustros, transitórios. Por isto mesmo, pouco fecundos na constituição e estratificação de uma consciência nacional - robusta, clara, definida, atuante." [1949] (Vianna, 1999: p. 317).
}

brasileiro e as suas marcações em diferentes manuais e obras durkheimianas. Exemplificando essa questão, notamos que Oliveira Vianna, no manual denominado Sociologie [1939], de Marcel Déat, faz importantes marcações em uma passagem que visa evidenciar o significado do conceito de Consciência Coletiva. Para Marcel Déat, sublinhado pelo pensador niteroiense, verificamos:

La conscience collective est réelle: que faut-il entendre par là? Qu'est ce qu'une conscience qui n'est pas celle d'une personne? (Cf. Roger Lacombe: La méthode sociologique de Durkheim.) Il n'est pas impossible de tirer des écrits de Durkheim une réponse assez simple. On oublie trop facilement que la conscience collective ensemble des représentations du groupe comme tel n'est pas seulement une réalité que l'on constante une force qui se manifeste: elle est un idéal, un système de valeurs. Peut-on dire dés lors, que l'existence sociale soit seulement une donnée, un fait objectif? C'est è cette riche ambigüité des représentations collectives qu'est suspense toute la sociologie an tant que système théorique et pratique. Qu'il suffise pour l'instant de noter que si l'existence de la conscience collective relève d'un jugement de valeur autant que d'un jugement de réalité, la question ne peut plus se présenter de la même façon. (Cf. ci-dessous, 3). (Déat, 1939, p. 80) ${ }^{10}$.

Nessa marcação de Oliveira Vianna, verificamos uma definição de Consciência Coletiva que se alinha expressivamente com o significado deste conceito tal como ele é empregado pelo intelectual brasileiro. $\mathrm{O}$ fato de Oliveira Vianna marcar essa passagem mostra, dentre outras coisas, a necessidade que sentia de assinalar e compreender a especificidade dessa categoria tão cara ao pensamento durkheimiano.

Acerca do conceito de Solidariedade Social, presente no obra A Divisão do Trabalho Social, notamos que Émile Durkheim mostra que a Solidariedade Mecânica, assim como a Solidariedade Orgânica, derivam da noção de Solidariedade Social; para o autor, tal noção representa uma condição

\footnotetext{
${ }^{10}$ Em tradução livre: "A consciência coletiva é real: o que isso significa? Que é um tipo de consciência que não é a de um único indivíduo? Não é possível retirar dos escritos durkheimianos uma resposta simples para essas questões. Esquecemo-nos muito facilmente que a consciência coletiva representa a união de todas as representações do grupo e, como tal, não é apenas uma realidade que manifesta uma força constante, ela é também um ideal, um sistema de valores. Então, podemos dizer que a existência social pode ser encarada como um dado ou um fato objetivo? É essa rica ambiguidade inerente às representações coletivas que sustenta toda a Sociologia como um sistema de teoria e prática. Todavia, agora, nos basta apenas notar que a existência da consciência coletiva não pode ser encarada tanto como um juízo valor quanto um juízo de realidade.” (Déat, 1939: p. 80).
} 
ou um estado de união de um determinado grupo. Assim, um grau maior ou menor de solidariedade resulta da comunhão de atitudes, de interesses e de sentimentos entre os membros de uma dada sociedade, de modo a constituir no grupo uma unidade sólida, capaz de resistir às forças exteriores e interiores ligadas a fomentação de insurgências ou oposições. Ou seja, reflete uma maior comunhão e partilha dos indivíduos em relação ao conteúdo de uma determinada Consciência Coletiva ou Comum (Durkheim, 1995). Em nossa pesquisa, comparamos as marcações de Oliveira Vianna que tinham relação com a noção de Solidariedade Social presente nas obras durkheimianas e nos mais variados manuais com as incorporações conceituais desta categoria feitas pelo pensador brasileiro e encontramos alinhamentos importantes no que concerne ao significado destes conceitos para ambos os autores.

O conceito Solidariedade Social não é empregado de maneira tão contundente por Oliveira Vianna em alguma de suas obras tal como é utilizado em Populações Meridionais do Brasil ${ }^{11}$. Deve ficar claro que não encontramos a utilização literal das duas variações durkheimianas para o conceito de Solidariedade Social, quais sejam: Solidariedade Mecânica e Solidariedade Orgânica ${ }^{12}$. Contudo, por conta de algumas análises nos materiais presentes no acervo do Museu Casa de Oliveira Vianna, podemos afirmar que o intelectual brasileiro teve um efetivo contato com uma determinada bibliografia que tratava dessas conceitualizações e isso refletiu em suas idéias sobre o Brasil e nossa formação.

Para Oliveira Vianna, a história apresenta exemplos de nações, sobretudo européias, que, de modo

\footnotetext{
${ }^{11} \mathrm{O}$ conceito de Solidariedade Social aparece de maneira mais contundente em Populações Meridionais do Brasil justamente porque ele foi, segundo nossa interpretação, de fundamental importância para que Oliveira Vianna edificasse seu diagnóstico acerca do Brasil e sua formação. A Insolidariedade e a Desintegração Social inerente ao nosso processo de formação são males que impossibilitam, para o autor, a nossa modernização e o nosso desenvolvimento. A pouca presença desta categoria em Instituições Políticas Brasileiras, acreditamos, acorre justamente porque nessa obra o pensador utiliza, em seu Volume I, o seu diagnóstico já pronto sobre nossa nação (transporta para a obra de 1949 as principais teses que cunhou em 1922) e não necessariamente expõe a constituição do mesmo.

${ }^{12}$ Referente ao pensamento durkheimiano, esses tipos de Solidariedade Social expressam, sobretudo, estágios diferenciados nos quais determinados agrupamentos sociais se encontram. Em sociedades menores (por vezes, tradicionais) que não sofreram com o advento da divisão do trabalho há mais solidariedade quanto maior for a amplitude ou a extensão de uma dada consciência coletiva. Já em sociedades consideradas modernas justamente por conta de integrarem a sua lógica a divisão do trabalho notamos que quanto maior for o grau de interdependência das funções desempenhadas pelos indivíduos, maior será o grau de união existente entre seus membros. Para a primeira forma que descrevemos damos o nome de Solidariedade Mecânica para a segunda nomeamos de Solidariedade Orgânica.
}

germinal, tinham em sua composição instituições capazes de forjar em seus membros um alto grau de união e, consequentemente, uma forte solidariedade social entre eles. Já no Brasil, segundo o pensador fluminense, tivemos uma autonomia exacerbada de nossos latifúndios, a qual dificultou nossa modernização justamento por impedir, dentre outras coisas, a formação de classes sociais diferenciadas e autônomas; o advento da divisão social do trabalho; o desenvolvimento de nossas cidades e conglomerados urbanos; e importantes avanços industriais e comerciais. Falando sobre isso o intelectual brasileiro afirma:

Cada núcleo fazendeiro é um microcosmo social, um pequeno organismo coletivo, com aptidões cabais para uma vida isolada e autônoma. Daí essa diferença entre a nossa e as sociedades européias. Nestas a divisão do trabalho, especializando as atividades, forma classes sociais interdependentes - e as une numa solidariedade estável. [1920] (Vianna, 2005: p. 238) ${ }^{13}$.

São justamente estes acontecimentos do mundo moderno (emergência de classes sociais diferenciadas, edificação de conglomerados urbanos, a experiência da divisão social do trabalho, etc.) que, de acordo com o pensamento durkheimiano, são fundamentais para se constituir um tipo diferenciado de solidariedade, qual seja: a Solidariedade Orgânica. Oliveira Vianna notou que essa complexificação, fundamental característica para identificar o avanço e a modernização de uma nação, não se fez presente no Brasil por uma série de motivos. O interessante é que o autor raciocina levando em consideração as características de um modelo europeu de formação e constituição de sociedade; para nós, reside no contato do intelectual brasileiro com as idéias que tratam desse modelo de formação, possíveis contribuições durkheimianas. Uma evidência disso é a marcação feita por ele em uma passagem da obra La Solidarité Sociale [1907] de G. L. Duprat [observa-se a data do manual, a qual é anterior à publicação de Populações Meridionais do Brasil]:

La coopération réglée n'est pas tout la solidarité sociale, pas plus que la synergie des éléments le l'être vivant dominé pas une volonté ferme n'est toute la solidarité organique. M. Durkheim

\footnotetext{
${ }^{13}$ Ou ainda, para Oliveira Vianna: "Em síntese: nem classe comercial, nem classe industrial; nem corporações urbanas. Na amplíssima área de latifúndios agrícolas, só os grandes senhorios rurais existem. Fora deles, tudo é rudimentar, informe, fragmentário. São os grandes domínios como que focos solares: vilas, indústrias, comércio, tudo se ofusca diante de sua claridade poderosa." [1920] (Vianna, 2005 p. 193).
} 
le reconnaît: La division du travail ne peut s'effectuer qu'entre les membres d'une société déjà constituée'. Mais, pour lui, la division du travail nait de la lutte pour l'existence, de la concurrence entre éléments: 'Si le travail se dévide davantage è mesure que les sociétés deviennent plus volumineuses et plus denses, c'est que la lutte pour la vie y est plus ardente'. Peut-on soutenir que la division du travail organique, la diversité des fonctions dans un être vivant provient de la concurrence des cellules, et ne voit on pas que c'est la multiplicité croissant des moyens d'existence commune qui provoque la différenciation des organes. De même, c'est, et de l'aveu même de M. Durkheim, 'du partage de fonctions jusque-là communes,' partage qui répond mieux que l'activité uniforme aux exigences de la vie collective, que résulte la spécialisation des éléments sociaux. C'est para solidarité que les individus replissent différentes fonctions sociales, et pour uni solidarité plus haut, plus féconde. En résume, la loi commune de da solidarité organique et de la solidarité sociale est la suivante: $L a$ densité croissant de l'agrégat amène, en même temps que sa différenciation progressive, une coordination plus efficace des activités diverse, une concentration plus grande de l'énergie collective en un pouvoir central que maintient l'interdépendance des parties spécialisées, devenues indispensables les unes aux autres. (Duprat, 1907, p. $20-21)^{14}$.

Os raciocínios expressos nos pensamentos de Oliveira Vianna (1920 e 1949) e nessa última citação de G. L. Duprat, a qual se ampara numa interpretação

\footnotetext{
${ }^{14}$ Em tradução livre: "As regras da cooperação não definem a solidariedade social; não mais que a sinergia dos elementos sociais que dominam o indivíduo, fazendo-os a estabelecer um compromisso firme com a sociedade, constituindo uma solidariedade orgânica. Sr. Durkheim reconheceu: 'A divisão do trabalho não pode se constituir entre os membros de uma sociedade que já se formou'. Pois, para ele, a divisão do trabalho nasceu da luta dos indivíduos pela existência, da competição inerente aos elementos de uma sociedade: ' $O$ trabalho se divide à medida que as sociedades se tornam maiores e mais densas justamente porque a luta pela vida é mais ardente'. Pode-se dizer que a divisão do trabalho orgânica, a diversidade das funções oriundas de células de competição, é fruto da crescente multiplicidade das meios de existência, causando assim, a diferenciação dos órgãos. Da mesma forma, ela é, segundo o Sr. Durkheim, 'a partilha das funções comuns até existentes', é a partilha que melhor atenda as exigências vida coletiva, resultando assim, na especialização dos elementos sociais. Esta é a solidariedade em que os indivíduos realizam diferentes funções sociais, unindo-se a uma solidariedade maior, mais fecunda. Em resumo, a lei comum da solidariedade orgânica e da solidariedade social é a seguinte: $O$ aumento crescente da densidade entre as diferentes funções (fios agregados), juntamente com a diferenciação progressiva, uma coordenação mais eficaz das diversas atividades, uma maior concentração de poder em um governo central e coletivo que consegue estabelecer e manter a interdependência entre as partes especializadas, tornando-as assim sempre dependentes e indispensáveis umas para as outras." (Duprat, 1907: p. 20 - 21). (Grifos do autor).
}

acerca do pensamento durkheimiano ligada ao significado do conceito de Solidariedade Orgânica, são muito parecidos. Aqui devemos destacar o vínculo da complexificação social como requisito fundamental para a modernidade. Tal preocupação, a qual expressa a constituição de um tipo novo de união, Solidariedade Orgânica, é inerente ao pensamento de Émile Durkheim e parece ter sido incorporada por Oliveira Vianna. No entanto, podemos perceber que Oliveira Vianna prefere denominar como Solidariedade Estável esse tipo específico de união existente entre os homens de uma sociedade considerada complexa, moderna e imersa na lógica inerente à divisão do trabalho.

Nesta parte da pesquisa acreditamos ter delineado com mais propriedade uma importante ligação existente entre Émile Durkheim e Oliveira Vianna que é perpassada pelos conceitos de Consciência Coletiva e de Solidariedade Social. De maneira geral, tivemos a oportunidade de visualizar que há uma semelhança evidente entre as teorizações durkheimianas sobre estes conceitos e o sentido dado a estas categorias por Oliveira Vianna. Para mostrar que essa ligação entre os dois autores era fruto de algumas leituras vinculadas ao pensamento de Émile Durkheim que foram realizadas pelo sociólogo brasileiro, apresentamos parte dos resultados de nossa pesquisa no Museu Casa de Oliveira Vianna. Com isso, podemos constatar que Oliveira Vianna apreendeu em suas leituras a significação destes dois conceitos inerentes ao pensamento durkheimiano e fez uso dos mesmos no momento em que constitui algumas de suas interpretações sobre a formação da nação brasileira.

\section{As Definições de Estado e de Comporativismo dadas por Émile Durkheim e Oliveira Vianna: Conceitualizações que Evidenciam Diferentes Ligações entre Ambos os Autores}

De maneira geral e sem a intenção de precisar todas as especificidades da definição de Émile Durkheim acerca de sua noção de Estado, notamos para o autor que esta categoria pode ser considerada como a instituição que representa e singulariza uma dada coletividade ao passo que consegue reunir em si mesma os valores, as normas e as regras que se acumularam e que fazem parte da tradição e da herança de uma sociedade. (Durkheim, 1983). Nesse sentido, o Estado consegue captar com relativa precisão os costumes e as representações sociais de um grupo e transformá-las em regras gerais a serem 
seguidas pelos indivíduos pertencentes a ele. Vale deixar claro que para o sociólogo francês o Estado é, de fato, uma extensão da sociedade da qual ele faz parte; contudo, ele traduz de maneira mais apurada e refinada a consciência comum inerente a ela. Dessa forma, o Estado seria e representaria uma evolução, em sentido e clareza, das normas, regras e representações sociais que fazem parte de um determinado agrupamento social.

Para Émile Durkheim, o Estado também é caracterizado pelo fato de ser composto por um grupo de funcionários sui generis capaz de representar e agir em nome da sociedade e seus interesses. Por fim, o intelectual francês acredita que o Estado possui e desempenha uma função liberatriz em relação ao indivíduo; tal percepção vai de encontro com a perspectiva liberal que ratifica a idéia de que há um maior grau de liberdade quando menor for a atuação do Estado junto à coletividade (Oliveira, 2009). Para nós, fica claro que quanto maior a ação do Estado, segundo Émile Durkheim, maior será o grau de liberdade dos indivíduos justamente porque seus direitos estariam mais assegurados ou resguardados. Vinculado a essa percepção, o intelectual francês afirma que o Estado também deve atuar levando em consideração a defesa do bem público e coletivo em detrimento da ação imprópria de determinados grupos que em nada representam ou agem em prol da maioria de uma dada sociedade. (Durkheim, 1983).

As características expostas acima daquilo que acreditamos ser para Émile Durkheim o Estado resguardam semelhanças com as definições dadas por Oliveira Vianna acerca dessa noção. Em nossa pesquisa, analisamos algumas observações do pensador brasileiro sobre a noção de Estado e as comparamos com suas marcações relacionadas a esse tema que tinham ligações com o pensamento durkheimiano.

Para o autor, nunca houve no Brasil uma instituição capaz reunir os anseios coletivos e agir fundamentalmente em benefício da comunidade, enfatizando assim, a promoção dos interesses públicos em detrimento dos interesses privados. Claramente, para o pensador, não houve em nossa história a reunião de instituições capazes de refletir de modo geral a sociedade da qual elas faziam parte ${ }^{15}$. Essas

\footnotetext{
${ }^{15}$ Segundo Oliveira Vianna: "Não há aqui, pois, nenhuma instituição, nenhuma autoridade, nenhum poder originariamente local, isto é, que tenha a sua origem nos próprios grupos locais. Todas as instituições locais existentes entre nós provêm do poder geral. Há, sem dúvida, os senados das câmaras com o seu luzido quadro de vereadores e procuradores, eleitos pelo povo. Estas corporações se fazem, porém, apenas centros do caudilhismo fazendeiro; o ardor combativo e a ociosidade relativa dos grandes potentados encontram nelas desafogo
}

características ausentes da sociedade brasileira em seu período colonial deveriam preceder uma instituição reguladora que aqui, segundo Oliveira Vianna, ainda não existe de modo efetivo (para Oliveira Vianna o Estado Brasileiro em seu aspecto formal existe, contudo, não atua levando em consideração determinados princípios fundamentais; um exemplo disso é a incapacidade de o Estado Brasileiro primar pela coletividade em detrimento de certos agrupamentos sociais).

Oliveira Vianna também admite, assim como Émile Durkheim, um vínculo profundo entre sociedade e Estado. Ao criticar a postura de alguns juristas brasileiros que desconsideram essa percepção, ele mostra o quão importante é pensar nesta instituição como uma extensão e um reflexo do meio social do qual ela faz parte e representa. Nesse sentido, a especificidade do Estado e de suas leis deve condizer com as particularidades da coletividade de que emanam ${ }^{16}$. Ao raciocinar assim, o intelectual fluminense se alinha a uma importante característica da definição durkheimiana dessa noção; nas palavras do pensador brasileiro:

Eles [conjunto de juristas criticado por Oliveira Vianna] como que estão nesta fase da filosofia política, em que o Estado é concebido como uma estrutura estranha à sociedade, ajustado a ela, vinda de cima, como que por direito

e diversão. Não são propriamente órgãos de utilidade coletiva, agindo em benefício da comunidade.” [1920] (Vianna, 2005: p. 301).

${ }^{16}$ Admitir essa relevante ligação entre o Estado e a Sociedade existente no pensamento de ambos os autores, em especial na definição que eles dão à noção de Estado, parece de uma grande obviedade. Contudo, e só a partir disso que conseguimos compreender os motivos pelos quais Oliveira Vianna, por exemplo, afirma, em Instituições Políticas Brasileiras [1949], que determinadas civilizações européias só estavam experimentando um regime democrático porque possuíam um Direito Costumeiro diferente do nosso. Ou seja, para o autor, a peculiaridade da formação destas civilizações possibilitou o nascimento de uma Consciência Nacional forte compatível com uma forma de organização democrática de governo. Assim, segundo o pensador brasileiro, notamos que as especificidades de um determinado poder regulador dependem das características existentes na coletividade que ele regula. De modo mais claro, a natureza do Estado deve se adequar, dessa forma, às particularidades da Sociedade de que ele faz parte. Essa questão, para nós, é de fundamental importância para enxergarmos a Sociologia Política de Oliveira Vianna. Por exemplo, Émile Durkheim, ao passo que observa a necessidade de instituir na França um Estado conformado em corporações com a capacidade de aumentar a união entre os indivíduos através do fortalecimento da moral profissional para conter o aumento do individualismo e da anarquia econômica, também expressa em seu pensamento esse importante vínculo entre a forma do Estado e as peculiaridades existentes na sociedade que é regulada por ele. Diante da "Anarquia Branca", do "Espírito de Clã", do legado deixado pela "Função Simplificadora do Latifúndio" e do fortalecimento de agrupamentos sociais atuando dentro do Estado em prol de seus interesses particulares e privados em detrimento dos anseios coletivos e da vida pública que Oliveira Vianna identifica no Brasil a necessidade de um Estado Forte, edificado, dentre outras coisas, por corporações. 
divino - e não emanado dela, partilhando das suas condições materiais e de espírito, vivendo a vida da sua 'cultura' e sofrendo a influência das suas transformações. [1949] (Vianna, 2005: p. 360).

Assim como Émile Durkheim, Oliveira Vianna também acredita que o Estado possui a fundamental função de garantir aos homens suas liberdades e direitos individuais, protegendo-os assim, da desmedida ação de uma minoria que não age em prol do bem comum e da vida pública. Em Populações Meridionais do Brasil, Oliveira Vianna constata que no Brasil Colônia não há uma instituição capaz de proteger os direitos coletivos em detrimento de dados agrupamentos sociais: "O homem que não tem terras, nem escravos, nem capangas, nem fortunas, nem prestígio sente-se aqui, praticamente, fóra da lei. Nada o ampara. Nenhuma instituição, nem nas leis, nem na sociedade, nem na família existe para a sua defesa" [1920] (Vianna, 1938, p. 201). Para Oliveira Vianna, os homens que possuem uma instituição capaz de guardar seus direitos, "São, por isso, autônomos. São, por isso, livres. Sob a ação permanente dessa confiança interior, o caracter se abdura, se consolida, se crystalisa e adquire a infragibilidade do granito ou do ferro" [1920] (Vianna, 1938, p. 201). Mais uma vez essa perspectiva interpretativa adotada pelo intelectual brasileiro acerca da noção de Estado resguarda importantes semelhanças com as definições de Émile Durkheim (o Estado, também para o intelectual fluminense, exerce uma função liberatriz em relação ao indivíduo).

Oliveira Vianna, na obra De la Division du Travail Social [1883], presente no acervo do Museu Casa de Oliveira Vianna, faz algumas marcações que possuem ligação com essas significações dadas por ele à noção de Estado. Para exemplificar essa questão selecionamos uma passagem sublinhada por Oliveira Vianna nesta obra que possui o seguinte conteúdo:

Notre méthode est donc tracée. Puisque le droit reproduit les formes principales de la solidarité sociale, nous n'avons qu'à classer les différentes espèces de droit pour chercher ensuite quelles sont les différentes espèces de solidarité sociale qui y correspondent. Il est, dés à présent, probable qu'il en est uni qui symbolise cette solidarité spéciale dont la division du travail est la cause. Cela fait, pour mesurer la part de cette dernière, il suffira de comparer le nombre des règles juridiques qui l'expriment au volume total du droit. Pour ce travail, nous servir des distinctions usitées chez les jurisconsultes. Imaginées pour la pratique, elles peuvent être très commodes à ce point de vue, mais la science ne peut se contenter de ces classifications empiriques et par à peu prés. La plus répandue est celle qui divise ie droit en droit public et en privé; le premier est censé régler les rapports de l'individu avec l'État, le second ceux des individus entre eux. Mais quand on essaie de serrer les termes de prés, la ligne de démarcation qui paraissait si nette au premier abord s'efface. Tout droit est privé, en ce sens que c'est toujours et partout des individus qui sont en présence et qui agissent; mais surtout tout droit est public, en ce sens qu'il est une fonction sociale et qu'es tous les individus sont, quoique à des titres divers, des fonctionnaires de la société. Les fonctions maritales, paternelles, etc., ne sont ni délimitées, ni organisées d'une autre manière que les fonctions ministérielles et législative, et ce n'est pas sans raison que le droit romain qualifiait la tutelle de munus publicum. [1883] (Durkheim, 1932, p. $32-33){ }^{17}$.

Por mais que Émile Durkheim não responda a pergunta que ele faz justamente por considerar anticientífico, nós acreditamos que ele, ao afirmar que certas funções do Estado são organizadas tal como algumas funções sociais, demonstra que há uma íntima ligação entre a sociedade e a instituição maior que a representa; nesse caso, pelo menos no modo como atua e organiza suas funções, o Estado é uma extensão e um reflexo do modo como a coletividade da qual ele faz parte está organizada. Seu estudo Lições de Sociologia, posterior à obra De la Division du Travail Social, que infelizmente não foi consultado por Oliveira Vianna, evidencia muito bem esta questão. Oliveira Vianna, em determinados

\footnotetext{
${ }^{17}$ Em tradução de Eduardo Brandão: "Nosso método já está traçado, pois. Uma vez que o direito reproduz as formas principais da solidariedade social, só nos resta classificar as diferentes espécies de direito para descobrirmos, em seguida, quais são as diferentes espécies de solidariedade social que correspondem a elas. É provável, desde já, que haja uma que simbolize essa solidariedade especial, de que a Divisão do Trabalho é a causa. Feito isso, para medir a importância desta última, bastará comparar a quantidade de regras jurídicas que a exprimem com o volume total do direito. Para esse trabalho, não podemos utilizar as distinções correntes entre os jurisconsultos. Imaginadas para a prática, elas podem ser cômodas desse ponto de vista, mas a ciência não pode se contentar com essas classificações empíricas aproximadas. A mais difundida é a que divide o direito entre direito público e privado. Ao primeiro caberia regular as relações entre individuo e o Estado; o segundo, as dos indivíduos entre si. Mas quando se procura examinar o termo de perto, a linha de demarcação, que parecia tão nítida à primeira vista, se apaga. Todo o direito é privado, no sentido de que são sempre e em toda parte indivíduos que se encontram em presença e que agem; mas, sobretudo, todo o direito é público, no sentido de que o direito é uma função social e de que todos os indivíduos são, embora a títulos diferentes, funcionários da sociedade. As funções maritais, paternas, etc. , não são nem delimitadas, nem organizadas de maneira diferentes das funções ministeriais e legislativas, e não é sem razão que o direito romano qualificava a tutela de munus publicum. Aliás, o que é Estado? Onde começa e onde acaba? Sabe-se quão controvertida é essa questão; não é científico fazer uma classificação fundamental basear-se numa noção tão obscura e mal analisada." (Durkheim, 1995: p. $32-33$ ).
} 
momentos, raciocina apresentado essa perspectiva acerca do Estado em algumas de suas explicações. Nesse sentido, não nos parece estranho o fato de o autor ter assinalado especificamente essa passagem em meio a esta importante obra durkheimiana.

Acerca do Corporativismo, notamos que ambos os autores acreditam na solução corporativa para constituir uma maior Solidariedade Social entre os indivíduos de suas nações. Também verificamos que as preocupações voltadas aos processos de modernização e as apreensões acerca das instabilidades sociais, políticas e econômicas de suas sociedades são de fundamental importância na elaboração e no embasamento de suas justificativas para a constituição de um Estado conformado em Corporações Profissionais.

De fato, aumentar a Solidariedade Social entre os indivíduos só é uma questão importante porque há por parte desses autores uma percepção específica acerca de seus contextos; para nós, essa percepção tem como eixo a ausência de estabilidade e de integração inerentes às suas nações, as quais, por sua vez, sofreram processos distintos de formação e desenvolvimento. No caso de Oliveira Vianna, a não integração e estabilidade advém de um processo específico de formação da sociedade brasileira; já para Émile Durkheim os motivos estão circunscritos à interpretação que ele conservava acerca das consequências negativas inerentes ao processo de modernização pela qual a França de sua época atravessava (destaca-se aqui, segundo o autor, a aumento crescente do individualismo na sociedade francesa). Dessa forma, para ambos os autores o Corporativismo possui a fundamental característica de produzir Solidariedade Social em condições estranhas à promoção da união entre os homens de uma mesma coletividade. Em nossa pesquisa, demonstramos essa percepção comparando as definições de ambos os autores sobre essa noção. No caso de Oliveira Vianna, destacaram-se os escritos sobre essa questão presentes na obra Problemas de Organização e Problemas de Direção [1952]. Já, em Émile Durkheim, conseguimos importantes contribuições sobre esse tema na obra Lições de Sociologia [1912], em especial nas três primeiras lições intituladas de A Moral Profissional.

\section{A Noção de Morfologia Social no Pensamento de Émile Durkheim e no de Oliveira Vianna: Outra Possibilidade Analítica de Nossa Pesquisa}

Ao nos debruçarmos sobre a questão da Morfologia Social em nossa pesquisa, notamos que para Émile
Durkheim ela representa um campo da Sociologia que tem por objetivo classificar os diversos tipos sociais levando em consideração as determinações naturais de uma dada coletividade; como os homens estão dispostos e organizados; como as principais estruturas e instituições estão estabelecidas; e quais as relações dos indivíduos com os meios físicos que ocupam. Além disso, o modo mais adequado de realizar essa tarefa é o de retomar e analisar as formas iniciais, por vezes menos complexas, de organização vinculadas às sociedades pesquisadas. Por fim, nota-se que Morfologia Social é uma importante área da Sociologia; contudo, o termo também pode indicar o conjunto de diferentes determinações (naturais, geográficas, topográficas, populacionais, etc.) que fazem parte de uma sociedade e que influenciam suas características culturais, políticas, sociais, econômicas, etc. Segundo o intelectual francês na obra As Regras do Método Sociológico:

Devemos, pois, escolher para a nossa classificação caracteres que sejam particularmente essenciais. É verdade que não poderemos conhecê-los senão quando a explicação dos fatos tiver progredido suficientemente. Estas duas partes da ciência são solidárias e progridem uma ligada à outra. Todavia, sem ir muito além no estudo dos fatos, não é difícil conjeturar de que lado é preciso buscar as propriedades características dos tipos sociais. Sabemos, efetivamente, que as sociedades são compostas de partes ajuntadas umas às outras. Uma vez que a natureza de todo o produto depende essencialmente da natureza, do número e do modo de combinação dos elementos componentes, estes caracteres são evidentemente os que devemos tomar por base; verificaremos, com efeito, no decorrer do trabalho efetuado, que é deles que dependem os fenômenos gerais da vida social. Por outro lado, como são de ordem morfológica, poderíamos chamar de Morfologia Social a parte da Sociologia que tem por tarefa constituir e classificar os tipos sociais. O princípio desta classificação pode ser tornado ainda mais claro. Sabe-se, sem dúvida, que as partes constitutivas de qualquer sociedade são sociedades mais simples do que a sociedade resultante. Um povo é produto da reunião de dois ou vários povos que o procederam. Assim, conhecendo a sociedade mais simples que tenha existido, não necessitaremos, para estabelecer nossa classificação, senão de ficar sabendo de que maneira essa sociedade se ajustava interiormente, e como se vão ajustando os compostos que dela derivam. [1895] (Durkheim, 2002a: p. 70).

Na obra Instituições Políticas Brasileiras [1949], Oliveira Vianna faz uso constante da concepção de 
Morfologia Social. Nesse sentido, o autor emprega da seguinte forma essa noção:

Uma mesma experiência que fracasse é renovada indefinidamente, desde que seja considerada 'liberal' ou 'democrática'. Não se procura saber a causa do fracasso: se está na psicologia mesma do povo; se nas condições peculiares da sua morfologia social; se nas deficiências da sua cultura política. Insiste-se sempre, e indefinidamente, na tentativa, renovando Constituições ou sistemas sucessivamente, convencidos todos de que o fracasso ocorrido tem causa exclusivamente nos homens, ou melhor, em alguns homens - os do 'partido de cima', e que, se substituirmos estes homens, mediante uma eleição ou mesmo uma revolução, os 'outros' - os que os substituírem, mostrarão a 'beleza do regime'... Não importa que uma experiência de mais de cem anos tenha mostrado, com rigor de uma lei, que estes 'outros', que sucederam aos do fracasso, falharam também e tanto quanto os outros. Este fracasso repetido não impede que os substitutos continuem a insistir na experiência - à maneira das moscas, quando tentam atravessar vidraças. [1949] (Vianna, 1999: p. 56 - 57).

Nessa citação, claramente o intelectual brasileiro se refere ao conceito de Morfologia Social como um conjunto de atributos específicos do Brasil (as especificidades naturais e organizacionais de nosso país que levaram a formação de um determinado tipo de povo com características culturais e sociais específicas) que não estão de acordo com as possíveis formas governamentais que aqui poderiam ser empregadas: a liberal ou a democrática. Oliveira Vianna, ao raciocinar e empregar o conceito de Morfologia Social dessa forma transpõe para sua teoria a significação durkheimiana que essa concepção possui. O motivo para crermos nessa nossa afirmação são algumas marcações de Oliveira Vianna em obras relacionadas ao pensamento durkheimiano que se vinculam com o conceito de Morfologia Social.

No manual denominado Sociologie Générale [1912], de Gaston Richard, temos uma relevante marcação de Oliveira Vianna acerca da noção de Morfologia Social inerente ao pensamento de Émile Durkheim. Essa marcação sintetiza com muita propriedade o que esta categoria significa segundo a definição durkheimiana da mesma:

Il este malaisé de voir à quelle solution $\mathrm{M}$. Durkheim s'est arrêté et, pour la critique non prévenue, c'est là qu'est la grande obscurité de son système. Dans l'Année sociologique qu'il a fondée et dirige depuis quatorze ans, on trouve une section, la sixième, consacrée à une science qui reçois le nom de morphologie sociale, M. Durkheim a pris soin d'en définir lui même l'objet. L'importance capitale de 'ce passage nous obligé a le citer in-extenso. 'La vie sociale repose sur substrat qui est déterminé dans da grandeur comme dans sa forme. Ce qui le constitue, c'est la masse de individus qui composent la Société, la manière dont ils sont disposés sur le sol, la nature et la configuration des choses dé 'toute sorte qui affectent les relations collectives. Suivant que la population est plus ou moins considérable, plus ou moins dense, suivant qu'elle este concentrée dans les villes ou dispersée dans la compagne, suivant la façon dont les villes et les maisons son construites, suivant que l'espace occupé par la Société est plus ou moins étendu, suivant o que sont les frontières qui le limitent, les voies de communication que le sillonnent, etc., ce substrat social est différèrent. Les Travaux qui traitent de ces questions relèvent actuellement de disciplines différentes. C'est la géographie qui étudie les formes territoriales des États; c'est l'histoire qui retrace 1"évolution des groupes ruraux ou urbains; c'est à la démographie que revient tout ce qui concerne la distribution de la population, etc. Il y a, croyons-nous, intérêt à tirer ces sciences fragmentaires de leur isolement et à les mettre en contact en les réunissant sous une même rubrique; elles prendront ainsi le sentiment de leur unité.' [...] 'La Morphologie sociale ne consiste pas l'ailleurs dans une simple science d'observation qui décrirait ces formes sans en rendre compte; elle peut et doit être explicative varient l'aire politique des peuples, la nature et l'aspect de lues frontières, l'égale densité de la population; elle doit se demander comment sont nés les groupements urbains, quelles sont les lois de leur évolution, comment ils se recrutent, quel est leur rôle, etc. Elle ne considère donc pas seulement le substrat social tout formé pour en faire une analyse descriptive; elle l'observe en voie de devenir pour voir comment il se forme. Ce n'est pas une science purement statique, amis elle comprend tout naturellement les mouvements d'où résultent les états qu'elle étudie'. (Richard, 1912, p. 46 - 47) ${ }^{18}$.

\footnotetext{
${ }^{18}$ Em tradução livre: "Nos anais denominados Année Sociologique, fundado e dirigido por quatorze anos por Émile Durkheim, encontramos uma seção, a sexta especificamente, que é dedicada à ciência designada como morfologia social; tal ciência teve o objeto cuidadosamente definido pelo próprio sociólogo francês. A importância dessa passagem nos obriga a citá-la integralmente. 'A vida social é baseada no tamanho e na forma de seu substrato. O qual é constituído foi constituídos pela massa de indivíduos que compõem a sociedade, como eles estão dispostos sobre o solo, a natureza e a configuração das coisas afetam as relações coletivas. Dependendo do tamanho da população, de sua densidade, de sua concentração nas cidades, de sua dispersão nos campos, do modo como as cidades e casas são construídas, da extensão do espaço ocupado pela sociedade, dos limites que determinam a comunicação, etc., cada substrato social
} 
Nessa parte de nossa pesquisa, buscamos evidenciar que há um vínculo importante entre o pensamento durkheimiano e o de Oliveira Vianna que é mediado pelo conceito de Morfologia Social. Nesse sentido, primeiramente, definimos como essa concepção aparece em meio ao pensamento durkheimiano. Dessa forma, para o intelectual francês, a Morfologia Social é uma área importante da Sociologia que leva em consideração as características naturais, organizacionais e materiais de uma dada sociedade para melhor compreender seus atributos sociais, culturais, políticos, morais, etc. Realizar estudos nessa área exige rigor e, para Émile Durkheim, a melhor maneira de realizar isso é retomar as formas primeiras, por vezes menos complexas, das coletividades que se pretende estudar e explicar. De maneira geral, acreditamos que pensador brasileiro desenvolveu todos estes pressupostos em determinados estudos, especialmente em Populações Meridionais do Brasil, no qual ele faz questão de enfatizar a importância de retornar a uma de nossas primeiras formas organizacionais (Brasil Colônia/Latifúndio) para melhor compreender nossas especificidades econômicas, culturais, sociais e políticas.

Em um segundo momento, comparamos as marcações de Oliveira Vianna que tinham algum vínculo com o conceito de Morfologia Social, tal como está presente no pensamento durkheimiano, com determinadas citações do pensador brasileiro presentes na obra Instituições Políticas Brasileiras. Com isso, notamos que há uma consonância entre ambas as concepções utilizadas pelos dois autores; ou seja, o significado de Morfologia Social presente no pensamento de Oliveira Vianna possui efetivas semelhanças com o do presente nas teorizações de Émile Durkheim.

Posteriormente, verificamos que, além de Émile Durkheim, um importante autor francês que contribuiu

\footnotetext{
será diferentes. Atualmente, há uma série de trabalhos de diferentes disciplinas que tratam dessa questão. Nesse sentido, temos a Geografia que estudas as diferentes formas territoriais dos Estados; a história que retrata a evolução dos grupos rurais e urbanos; a demografia que traça tudo aquilo que concerne à distribuição da população, etc. Acreditamos que o maior proveito para o conhecimento só pode ser gerado ao passo que colocamos essas ciências em contato, unindo-as para juntas formarem um único cabeçalho. [...] 'A Morfologia Social não uma simples ciência da observação que descreve profundamente essas formas. Ela também deve explicar a natureza política dos povos, de suas fronteiras, de suas leis, de sua densidade populacional. Deve indagar como nascem os grupos urbanos, quais são as leis de sua evolução, como eles se unem, qual são os seus papéis, etc. Ela, portanto, ela não deve realizar acerca do substrato social uma análise puramente descritiva; sua função também é a de compreender como ele é formado. Ou seja, ela não é uma ciência puramente estática; ela também busca compreender os movimentos naturais que levaram a constituir os estados ou momentos que ela está estudando." (Richard, 1912: p. $46-47$ )
}

com Oliveira Vianna acerca deste conceito foi Maurice Halbwachs, o qual, por sua vez, foi um notório discípulo durkheimiano que emprestou muitas idéias do sociólogo francês, principalmente àquelas vinculadas a concepção de Morfologia Social. De fato, as muitas obras deste autor presentes no acervo revelam que houve o contato de Oliveira Vianna com esta concepção que foi fortemente mediado pelos escritos desse pensador. Contudo, as marcações do pensador brasileiro em outras obras sugerem que ele sabia que o intelectual que concebeu a idéia de Morfologia Social foi Émile Durkheim.

Por fim, é interessante notarmos que Oliveira Vianna não faz um uso corrente da noção de Morfologia Social em Populações Meridionais do Brasil. A bibliografia consultado por nós indica que essa não utilização se justifica porque o autor não tinha entrado em contato com a definição dessa categoria em anos anteriores à publicação de sua grande obra. Nesse sentido e verificando o quão novo era esse campo da Morfologia Social, e essa é uma de nossas hipóteses, acreditamos que Oliveira Vianna usa, em determinados momentos, a noção de Morfologia Social com a intenção de inserir seu grande estudo da década de vinte em um campo científico visto como mais moderno e atual, afastando-se assim, em Instituições Políticas Brasileiras, por exemplo, da profunda ligação metodológica que Populações Meridionais do Brasil tinha com a escola de Le Play ${ }^{19}$.

\footnotetext{
${ }^{19}$ Pistas acerca dessa mudança são dadas por André Veiga Bittencourt na dissertação denominada "O Brasil e suas Diferenças: Uma leitura genética de Populações meridionais do Brasil”. Segundo o autor: "O olvido da Escola foi, ainda segundo os autores, motivado principalmente pela vitória da tradição durkheimiana no interior da universidade, e cuja consequência foi o apagamento da vertente rival nas narrativas sobre o desenvolvimento e institucionalização das ciências sociais na França. Por outro lado, o caráter eminentemente conservador das teorias de Le Play fez com que a tradição marxista também atacasse ou ignorasse as formulações e resultados de pesquisa obtidos por esses sociólogos. Observemos que mesmo no momento de auge da Escola, na passagem do século XIX para o XX, seus autores sempre se mantiveram distantes do ambiente universitário francês, trabalhando muitas vezes para a iniciativa privada ou em escolas próprias, como é o caso da École des Roches - fundada por Demolins e que existe até hoje - e mantendo como catalisador dos debates e pesquisas a revista 'Science Sociale', dirigida também por Edmond Demolins. Um último aspecto que contribuiu fortemente para a rejeição da Escola de Le Play foi a instrumentalização de algumas idéias de Le Play pelo discurso do Marechal Pétain, principal nome do regime de Vichy, sobretudo no que diz respeito à importância do fortalecimento de uma ordem moral no país e o caráter eminentemente reformador de sua doutrina social (Kalaora e Savoye, 1989: 44-7), o que de algum modo nos aproxima, guardadas as devidas proporções, da relação criada entre Oliveira Vianna e sua atuação no Estado Novo.” (Bittencourt, 2011: p. 50 - 51). Destaca-se, aqui, o diagnóstico de André Veiga Bittencourt que evidencia a vitória da escola durkheimiana. Para nós, esse fato não ficou alheio à percepção de Oliveira Vianna, o que percebemos é justamente o contrário. Diante deste dado, é interessante atentar para uso do conceito de Morfologia Social em uma de suas últimas obras.
} 


\section{Conclusão}

Em relação ao artigo, acreditamos que conseguimos expor em linhas gerais e com relativo sucesso os propósitos e os resultados da pesquisa denominada A Presença de Émile Durkheim em Oliveira Vianna: Contribuições ao Pensamento Social e Político Brasileiro. Acreditamos que realizamos esta atividade com um relativo sucesso justamente porque a necessidade de sintetizar toda a pesquisa colabora para a realização de algumas imprecisões e reduções, afinal, um artigo possui um fôlego diferenciado quando comparado a uma dissertação. Tal formato científico de exposição impossibilita uma extensa evidenciação dos materiais e dos recursos que sustentam nossas hipóteses e afirmações (aqui, especificamente, nos referimos à impossibilidade e apresentar de modo mais extenso o material por nós pesquisado no $\mathrm{Museu}$ Casa de Oliveira Vianna). Diante deste fato, a única constatação positiva vincula-se a possibilidade de, ao passo que determinadas fragilidades no artigo forem identificadas pelo leitor, o mesmo terá a oportunidade de, em uma segunda oportunidade, entrar em contato com a versão final da pesquisa na base de dissertações do Programa de Pós-Graduação em Ciências Sociais da Universidade Estadual de Maringá no momento em que a mesma for disponibilizada.

Voltando à pesquisa, acreditamos que ela demonstrou que há importantes vínculos entre o pensamento de Oliveira Vianna e o de Émile Durkheim. Nesse sentido, verificamos, após o fim de nossas investigações, que o sociólogo francês contribuiu fundamentalmente para o pensamento de Oliveira Vianna ${ }^{20}$. Tais contribuições são visíveis quando pensamos em alguns conceitos e noções especificamente, são eles: a noção de Consciência Coletiva, Solidariedade Social, Morfologia Social, Estado e Corporativismo.

As várias marcações de Oliveira Vianna acerca do pensamento de Émile Durkheim presentes tanto nas obras durkheimianas, quanto em trabalhos que buscavam comentar o pensamento do sociólogo francês foram um importante recurso para a realização de nossa pesquisa. Para nós as palavras sublinhadas pelo intelectual brasileiro conduziram-nos ao itinerário de leitura realizado pelo pensador fluminense acerca das idéias e dos conceitos durkheimianos. Por isso buscamos, em todas nossas comparações, assinalar as

\footnotetext{
${ }^{20}$ Isso não significa excluir do pensamento de Oliveira Vianna as contribuições de muitos outros pensadores e suas respectivas teorias. A nossa intenção é, na verdade, situar com mais clareza as contribuições durkheimianas no sentido de iluminar uma questão que até então era extremamente obscura quando contraposta com uma importante bibliografia que comentava Oliveira Vianna.
}

datas das obras que eram comparadas, evitando assim, possíveis anacronismos e imprecisões.

Acreditamos que as palavras sublinhadas por Oliveira Vianna em relação a determinadas conceitualizações e noções durkheimianas foram valiosas para ultrapassarmos uma análise direta e puramente bibliográfica que busca evidenciar as aproximações conceituais e teóricas existentes entre os dois autores. Dessa forma, as marcações do sociólogo brasileiro configuram-se como um dado empírico utilizado em nossa pesquisa para auxiliar na investigação de nossos objetivos e na verificação de nossa hipótese. Esse dado mostra, sobretudo, as leituras acerca do pensamento durkheimiano que foram realizadas pelo intelectual brasileiro.

Nesse sentido, notamos que houve por parte de Oliveira Vianna a intenção de compreender especificamente determinadas idéias e conceitos inerentes ao pensamento de Émile Durkheim. Para nós, tudo fica mais claro quando vemos a transposição do conteúdo destas idéias e conceitos para algumas teorizações do sociólogo niteroiense sobre o Brasil em algumas de suas principais obras. De acordo com nossa percepção, foi exatamente isso que evidenciamos com nossa pesquisa.

Nosso trabalho também apresentou alguns pontos de distanciamento entre Émile Durkheim e Oliveira Vianna. Por exemplo, notamos que a mais importante distância existente entre eles vincula-se ao diagnóstico que ambos os autores fizeram acerca de suas realidades. Para nós, os dois pensadores enxergavam nos contextos em que estavam localizados a inexistência de estabilidade social, a falta de integração, a ausência de união e solidariedade entre os indivíduos e, por consequência, a iminência do esfacelamento e da descoesão social. Todavia, a desintegração social era para Émile Durkheim fruto do processo de modernização pela qual a França estava passando. Já para Oliveira Vianna, a insolidariedade brasileira é resultado das especificidades circunscritas a nossa formação, as quais impediram a edificação de um processo bem acabado de desenvolvimento.

Émile Durkheim é um importante autor da Sociologia Geral muito presente nos cursos de graduação em Ciências Sociais de nosso país. No entanto, dificilmente se busca estudar as relações e ligações de seu pensamento com determinados trabalhos vinculados ao nosso Pensamento Social e Político. Nesse sentido, acreditamos que com nossa pesquisa conseguimos delinear com mais propriedade a presença do sociólogo francês nessa tão importante área das Humanidades Brasileiras.

Oliveira Vianna constituiu seu pensamento através de significativas contribuições; pensar o 
contrário disso é negar uma colocação óbvia. A seara de pensadores e pesquisadores que fazem parte do arcabouço intelectual do autor é tão grande que, inclusive, limitamos nosso estudo ao vínculo específico existente entre ele e Émile Durkheim, e a determinados eixos conceituais e temáticos, os quais, em meio ao debate hoje existente, também são associados, por alguns de seus comentadores, a outros autores. Em meio a essa diversidade, buscamos em nossa pesquisa demonstrar quais as contribuições do sociólogo francês ao pensamento do autor brasileiro. Nesse sentido, além de mostramos quais foram essas contribuições, de maneira geral, conseguimos evidenciar que Émile Durkheim tem um peso considerável no pensamento de Oliveira Vianna.

\section{Referências}

Bittencourt, André. 2011. O Brasil e suas diferenças: uma leitura genética de Populações meridionais do Brasil. Dissertação de Mestrado, Universidade Federal do Rio de Janeiro.

Botelho, André e Schwarcz, Lilia Moritz. 2011. Pensamento Social Brasileiro: um Campo Vasto Ganhando Forma. Revista Lua Nova, 82: 11-16.

Bresciani, Maria Stella Martins. 2007. O charme da ciência e a sedução da objetividade: Oliveira Vianna entre intérpretes do Brasil. 2 ed. São Paulo: UNESP.

Déat, Marcel. 1939. Notions de Sociologie. Paris: Libraire Félix Alcan. 10. ed. Disponível em: Acervo do Museu Casa de Oliveira Vianna. Acesso em: 14 julho 2011.

Duprat, Guillaume Léonce. 1907. La Solidarité Sociale: ses causes, son évolution, ses conséquences. Paris: Octave Doin, Éditeur. Acervo do Museu Casa de Oliveira Vianna.

Durkheim, Émile. 1995. A divisão do trabalho social. Trad. Eduardo Brandão. São Paulo: Martins Fontes.

Durkheim, Émile. 2002a. As regras do método sociológico. 17. ed. (Maria Isaura Pereira de Queiroz, trad.). São Paulo: Companhia Editora Nacional.
Durkheim, Émile. 1972. Educação e Sociologia. 8. ed. (Professor Lourenço Filho, trad.). São Paulo: Edições Melhoramentos.

Durkheim, Émile. 1932. De la Division du Travail Social. 6. ed. Paris: LABRAIRE FÉLIX ALCAN. Disponível em: Acervo do Museu Casa de Oliveira Vianna. Acesso em: 07/07/2011.

Durkheim, Émile. 1983. Lições de sociologia: a Moral, o Direito e o Estado. Trad. J. B. Damasco Penna. São Paulo: Editora da Universidade de São Paulo.

Mannheim, Karl. 1976. Ideologia e Utopia. 3. ed. (Sérgio Magalhães Santeiro, Trad.). Rio de Janeiro: Zahar Editores.

Meucci, Simone. 2001. Os Primeiros manuais didáticos de Sociologia no Brasil. Estudos de Sociologia, 6(10): 121-158.

Oliveira, Márcio de. 2009. Durkheim, a política e o estado. Curitiba: XV Congresso Brasileiro de Sociologia.

Richard, Gaston. 1912. Sociologie Générale: Et Les Lois Sociologiques. Paris: Octave Doin Et Fils, Éditeurs. Disponível em: Acervo do Museu Casa de Oliveira Vianna. Acesso em: 14 jul. 2011.

Tôrres, Vasconcelos. 1956. Oliveira Vianna - sua Vida e sua Posição nos Estudos Brasileiros de Sociologia. 1 ed. Rio de Janeiro: Livraria Freitas Bastos S.A.

Vianna, Oliveira. 1999. Instituições Políticas Brasileiras (Primeiro e Segundo Volume). Brasília: Conselho Editorial do Senado Federal. Disponível em: <http:// www.senado.gov.br/web/conselho/conselho.htm>. Acesso em: 20 setembro 2010.

Vianna, Oliveira. 2005. Populações Meridionais do Brasil: Populações Rurais do Centro Sul (PaulistasFluminenses-Mineiros). Brasília: Conselho Editorial do Senado Federal. Disponível em: <http://www. senado.gov.br/web/conselho/conselho.htm $>$. Acesso em: 20 setembro 2010.

Vianna, Werneck Luiz. 1991. Americanistas e Iberistas: A Polêmica de Oliveira Vianna com Tavares Bastos. DADOS: Revista de Ciências Sociais, 34(2): 145-189.

Vieira, Evaldo. 1981. Autoritarismo e Corporativismo no Brasil: Oliveira Vianna \& Companhia. 2. ed. São Paulo: Cortez. 